\title{
Moral y don en las reparaciones económicas a las víctimas del terrorismo de estado en Argentina
}

Maricel Alejandra López*

Resumen: Este articulo pretende abordar la experiencia de las políticas de reparaciones económicas que implementó el estado Argentino frente sus crímenes cometidos durante la última dictadura militar (1976-1983) y los valores y actitudes que construyen las víctimas y familiares en respuesta a las indemnizaciones que el Estado propone como forma de reparación. Considero que analizar estas reparaciones a la luz de la Teoría del don de Marcel Mauss, puede traer luz sobre este hecho social y los debates éticos y políticos que ha suscitado.

Palabras claves: Reparaciones económicas. Moral. Don. Dictadura militar. Argentina.

\section{Introducción}

Este Articulo pretende abordar la experiencia de las políticas de reparaciones económicas que implementó el estado Argentino frente sus crímenes cometidos durante la última dictadura militar (1976-1983) y los valores y actitudes que construyen las víctimas y familiares en respuesta a las indemnizaciones que el Estado propone como forma de reparación.

* Doctorado en Ciencias Antropológicas. Facultad de Filosofía y Humanidades. Universidad Nacional de Córdoba. Investigadora FONCyT - Argentina. E-mail: maricellopez921@hotmail.com 
Las obligaciones resultado de las relaciones de intercambio, son constitutivas de las relaciones sociales y actúan como sostén de las relaciones sociales que allí se constituyen. A partir de este planteo inicial intentaré analizar el don en relación las reparaciones económicas que recibieron las victimas e terrorismo de estado en la Argentina, durante la década del 90, ya que puede iluminar la comprensión de este hecho social, sus prácticas, las relaciones sociales existentes, los "bienes" y valores que circulan, así como los grupos que intervienen en los actos de intercambio y las estrategias elaboradas por los diferentes individuos y grupos en respuesta a las "indemnizaciones" que el Estado propuso como forma de reparación ante sus crímenes.

Cabe señalar que abordar el tema de las reparaciones en el periodo de transición, implica pensar como se articulan procesos locales, nacionales y transnacionales, en los cuales las medidas llevadas adelante para reparar los daños ocasionados por las el terrorismo de estado son resultado de la lucha de los organismos de Derechos Humanos, y su relación con el estado y los organismos Internacionales. Permite dar cuenta de cómo la aplicación de los "derechos Universales" se resignifica en la singularidad de contextos nacionales, en los cuales las trayectorias y grupos específicos, adquiere características particulares.

En la Argentina las diferentes experiencias de represión política han dado lugar a la conformación de una serie de organizaciones que se nuclean bajo el nombre de "Organismos de Derechos Humanos". Las cuales desde hace treinta y seis años han llevado adelante reclamos de justicia ante los crímenes del Estado, y en el caso que me ocupa del Terrorismo de Estado durante la última dictadura militar (1976-1983).

El foco como ya señalé estará puesto en una de las políticas estatales que en la Argentina se dio con respecto a la dictadura y a las violaciones a los Derechos Humanos que es la reparación económica a las víctimas del Terrorismo de Estado. Para ello, luego de referir al contexto y las leyes que las instituyen, emprenderé el análisis de los dichos de diferentes actores para desde allí acceder a cuestiones más generales respecto a los debates éticos y políticos de las organizaciones de Derechos Humanos en relación a las reparaciones, tanto en el ámbito público como privado. 


\section{Medidas de reparación en los primeros años de democracia}

El tratamiento de las violaciones a los derechos humanos cometidas en Argentina entre los años 1974 y 1983 incluyó una amplia política de reparación.

El proceso de transición en este país estuvo signado por la creación de la Comisión Nacional sobre Desaparición de Personas $(\mathrm{CONADEP})^{2}$ y por el juzgamiento de los altos jefes militares ${ }^{3}$. Acciones que repercutieron en la opinión pública nacional e internacional (GUEMBE, 2004, p. 4)

En el caso de Argentina, la idea de Derechos Humanos está fuertemente asociada al tema de los desaparecidos políticos, o como lo señala Da Silva Catela "el problema de los desaparecidos absorbe y concentra el núcleo de lo que en ese país se considera Derechos Humanos" (2001), dejando en un segundo plano otras víctimas como ex presos políticos y exiliados.

El seguimiento del proceso de reparación del estado por los delitos de lesa humanidad da cuenta de esto, ya que en sus antecedentes iniciales las primeras medidas estuvieron orientadas principalmente a la reparación de familiares de desaparecidos ${ }^{4}$.

Durante los años 1984 y 1985 se dictaron una serie de leyes de carácter reparatorio. Los beneficios establecidos en estas normas no fueron exclusivamente económicos ni se trató de una política en términos estrictos, aunque son disposiciones que tuvieron mucha importancia para reparar situaciones particulares que afectaban a los beneficiarios.

Otro de los focos de estos primeros años fue el dictado de normas que tuvieron por objeto resolver el problema de trabajadores que habían sido expulsados o cesanteados de sus cargos públicos durante la dictadura ${ }^{5}$, los que permitió subsanar situaciones de injusticia de grupos específicos. Estas medidas obedecieron, en términos generales, a la presión ejercida por los propios afectados con independencia del apoyo del resto de la sociedad.

Por su parte, algunas personas que habían estado detenidas a disposición del Poder Ejecutivo Nacional (en adelante PEN), en virtud del estado de sitio, iniciaron juicios civiles en los que reclamaron 
al Estado la indemnización de daños y perjuicios ${ }^{6}$. El reclamo de los que habían sido presos políticos dio comienzo a un debate en la órbita del Poder Judicial que contribuyó posteriormente a la sanción de medidas reparatorias de carácter legislativo.

Los organismos de derechos humanos, poco a poco, comenzaron a hablar de la necesidad de que el Estado reparara las violaciones a los derechos humanos de una manera integral. Así, en el año 88, organismos y juristas formaron el Grupo de Iniciativa para una Convención contra las Desapariciones Forzadas de Personas, el cual elaboró un proyecto de Declaración sobre la Desaparición Forzada de Personas para ser presentado a la Asamblea General de las Naciones Unidas y un anteproyecto de Convención Internacional para la prevención y la sanción de este delito. Este reclamo se enmarcó en el derecho internacional, donde se señalaron las obligaciones que surgen para los Estados cuando este comete graves violaciones a los derechos humanos y especialmente la necesidad de esclarecer lo ocurrido a las víctimas e imponer sanciones a los responsables y al mismo tiempo se introdujo en el debate local, la obligación del Estado de otorgar una reparación económica.

\section{Las reparaciones económicas}

Durante las presidencias de Carlos S. Menem (1989-1999) se dictaron las normas más importantes de reparación económica para las víctimas de las violaciones a los derechos humanos cometidas entre 1974 y 1983.

Las mismas se implementaron en 1992 para los ex presos políticos y en 1994 para los familiares de los desaparecidos políticos. La misma fue resultado de una disposición de la Comisión Interamericana de Derechos Humanos ${ }^{7}$ (en adelante CIDH), donde como respuesta a los reclamos que venían llevando a cabo los Organismos de Derechos Humanos en el ámbito internacional, instaron a varios Estados latinoamericanos, que transitaron por periodos dictatoriales en los 70, a indemnizar a las víctimas de su accionar represivo.

La decisión política del estado de reparar económicamente a las víctimas, lejos de ser vista como una respuesta a los reclamos de 
justicia de los Organismos de Derechos Humanos, generó grandes conflictos al interior de los mismos en torno a su legitimidad, ya que "puso en juego la noción de Derechos Humanos en relación con la de dinero, cuando ambas parecen irreconciliables, situadas en polos opuestos en las representaciones que de ellas se construyen". (TELLO, 2003, p. 38-39).

Es importante señalar que este período en el que se inscriben las reparaciones económicas coincide con la definitiva paralización de la actuación de la justicia. Recordamos que por iniciativa de Raúl Alfonsín se sancionaron en los años 1986 y 1987 dos normas, la ley de "punto final" " y la de "obediencia debida", que concluyeron la persecución penal del grueso de los militares y miembros de las fuerzas de seguridad por su participación en el terrorismo de Estado. Carlos Menem perdonó mediante indulto presidencial ${ }^{10}$ a los miembros de las juntas militares que habían sido condenados en el Juicio a las Juntas y a unos pocos militares de alto rango que estaban aún sometidos a proceso. Paralelamente, indultó a algunos jefes de la guerrilla que se encontraban procesados.

Este contexto de impunidad hace que las reparaciones económicas sean aun más conflictivas para los Organismo ya que se pone en tensión lo que se considera justicia y Derechos Humanos en la sociedad argentina y a su vez pone en cuestión la relación que mantienen los Organismos con el Estado que, "por un lado han logrado legitimar la problemática de los desaparecidos al punto de institucionalizarla en organizaciones y secretarías de Estado, y por el otro se muestran disconformes con las políticas que éste implementa" (TELLO, 2003, p 39).

\section{Dar, Recibir, Devolver}

Para emprender el análisis de las reparaciones a partir de la teoría del don de Marcel Mauss considero necesario realizar un señalamiento preliminar sobre los aspectos de esta obra que considero pertinentes para abordar el tema.

Primero, mencionaré que la noción de "dar, recibir, devolver" será el sustrato del esquema de análisis. Desagregando esta matriz, 
tomaré el dar como un acto de reconocimiento social. El recibir, como una "carga" redimida con el devolver. Pero plantearé que aquí el mana y la obligación de devolver, presente en "la fuerza de la cosa dada" serán claves para entender el universo de las reparaciones económicas.

Al abordar esta cuestión en Mauss, cabe señalar que lo que interesa son los motivos de la acción humana, los lazos morales y la ética compartida, que llegan inclusive a ser fundamental en las decisiones de los individuos. Debemos por esto, insistir en la importancia de concebir el esquema "dar, recibir, devolver" como un intercambio de obligaciones morales.

Incluso, la economía del don tiene su particularidad en las relaciones de poder (inscriptas en la subordinación que impone el dar al que debe devolver). Además, el intercambio no se realiza individualmente, sino que se cambia en tanto que personas-morales.

Tomaremos, también aquello de que las cosas no se desprenden completamente de las personas que las cambian.

\section{Reparaciones a los ex detenidos políticos}

En el 92 el Congreso Nacional sancionó la ley 24.043¹. Esta norma otorgó un beneficio a las personas que antes del 10 de diciembre de 1983 hubieran estado detenidas a disposición del PEN, en virtud de la declaración del estado de sitio. También para aquellos civiles que fueron detenidos por decisión de tribunales militares, con o sin sentencia, que hubiera o no iniciado juicio por daños y perjuicios. No podían solicitar el beneficio quienes hubieran percibido alguna indemnización en virtud de sentencia judicial por los mismos hechos.

La solicitud del beneficio se tramitó ante el Ministerio del Interior, las víctimas recibieron una suma equivalente a la treintava parte de la remuneración mensual asignada a la categoría superior del escalafón para el personal civil de la administración pública nacional, al día del cobro del beneficio, por cada día que duró la medida de detención ${ }^{12}$. 
Según lo establecido por esta ley y en su resolución reglamentaria se pagaron $\$ 74$ por cada día de detención. Las indemnizaciones se hicieron efectivas en Bonos de consolidación de la deuda pública - específicamente Bocon ${ }^{13}$ Proveedores Serie II. Se trata de documentos a través de los cuales el Estado argentino reconoce la existencia de una deuda y garantiza su pago. Es decir que el Estado en lugar de pagar en dinero entrega estos títulos de deuda que los tenedores posteriormente canjearán por dinero.

A nivel público, desde un posicionamiento moral y político, la Asociación de Ex Detenidos Desaparecidos ${ }^{14}$ rechazó y criticó el cobro de las "indemnizaciones":

[...] Lamentablemente, lo que el Estado más que reconocer recibe con beneplácito, es que el genocidio pueda tener un precio: tantos dineros por tantos desaparecidos en el álbum familiar [...] Este Estado, se separa de los diferentes regímenes gubernamentales en cuanto a las coyunturas y metodologías políticas, pero se identifica con ellos en cuanto sostén burocrático de los intereses de la burguesía, no busca hacer justicia. No la justicia íntegra que reclamamos. [...] Creemos que no todo puede canjearse, ni por dinero ni por un equivalente a aquello que pretende ser intercambiado. No todo, porque algunos bienes no tienen igual, ni siquiera entre si, por ejemplo la vida, la tierra, la cultura, la libertad. Afirmamos que las reparaciones, así planteadas, esto es, con impunidad, nos involucran en una negociación. ("Reparación económica, debate y reflexión.” Diario de las Madres, $\mathrm{N}^{\mathrm{O}}$ 141, Mayo de 1997).

La articulación vida-dinero que implican las reparaciones económicas, tanto por las desapariciones como por la prisión política, es conflictiva para los actores, desde lo moral señalan la ilegitimidad de cobrar y dan cuenta de la tensión existente entre La moral "revolucionaria" (atribuida a los militantes y a los familiares) y la "moral capitalista" (atribuida al estado), que ubicadas en polos opuestos quiebran la idea de una concepción única sobre derechos humanos. 
Por otra parte, también desde moral deslegitiman el cobro, aun si individualmente se aceptara el dinero para utilizarlo con fines colectivos en la lucha por los derechos humanos ya que consideran que colectiva y políticamente, esta acción implica abdicar ante las condiciones que el beneficio impone.

Innegablemente con ese dinero se pueden hacer muchas cosas, para sí como 'para la causa' (pero) cada billete guardado o donado supone la aceptación de esa dicotomía excluyente: justicia o dinero. Con él podrán hacerse muchas cosas, lo que no podrá lograrse es borrar la impronta de esa abdicación, ya que con el dinero se aceptan también las condiciones en que ese beneficio se otorga, más allá de la voluntad individual de los solicitantes. Y esto porque la ética no es únicamente un código de legitimidad personal ('yo cobro, pero continúo la lucha') ("Reparación económica, debate y reflexión.” Diario de las Madres, No 141, Mayo de 1997).

En lo expuesto en este fragmento subyace la lógica del don en todos su aspectos, ya que se cree que la aceptación del dinero en tanto (don), implica un mana, una obligación de devolver, especifico que es la Abdicación (contradon) implícita en la aceptación de las condiciones que el beneficio otorga. Inclusive, cuando se señala que esto va mas allá de la "voluntad individual", haciendo referencia a quienes consideran que el dinero puede ser usado para la causa, y que la "ética no es un código de legitimidad personal" confirma lo que señala Mauss cuando sostiene el intercambio no se realiza individualmente, sino que se cambia en tanto que personas-morales, pertenecientes a grupos.

A diferencia de la Capital, donde el rechazo a las reparaciones económicas adquirió dimensión pública, en Córdoba no fue así. Los ex presos políticos no estaban organizados y las decisiones en la mayoría de los casos se tomaron de manera individual, o a lo sumo quienes participaban o estaban próximos a la Asociación de Familiares de Desaparecidos, lo conversaron con los referentes locales.

A partir de entrevistas realizadas a ex presos políticos observé que los relatos que dan cuenta de cómo vivieron esa experiencia, 
recuerdan haber tomado en soledad, la decisión de aceptar la reparación económica, sin mayores cuestionamientos morales. Algunos recuerdan haber escuchado las declaraciones de Hebe de Bonafini con duras críticas a quienes aceptaran cobrar y otros que recién se enteraron muchos años después, a partir de retomar la militancia.

Acepté dinero, va bonos por la reparación, acá en Córdoba no generó lo que en Buenos Aires con la Hebe [...] y ahora yo apoyo la pensión universal, pero no le haría juicio al estado por mis secuelas, era un riesgo posible y yo elegí correrlo [...] Me prendó solo en los reclamos colectivos, en los individuales no. (JUAN CARLOS, Octubre 2011).

Acá la mayoría lo cobro. Yo lo cobré, yo me enteré por una sobrina mía porque yo había dejado la militancia y una sobrina que es abogada me dijo "tía están pagando unas reparaciones" y ella me hizo los tramites y yo fui a cobrarlo a Buenos Aires así como si tal cosa fuera. [...]Yo no recuerdo si había discusiones...

A mí, mi sobrina me hizo el trámite, me citaron de Buenos Aires, me pagaron y me vine a Córdoba y seguí mi vida normal, pero yo no estaba en contacto con nadie, yo salí de la cárcel y me dedique solo a trabajar [...] Después con los años, recién cuando empecé a militar, hará unos 5 años que me enteré que había habido tantos problemas." (ROSA, Noviembre 2011).

Juan Carlos a diferencia de Rosa, si estaba vinculado con los Organismos de Derechos Humanos desde que salió de la cárcel, estuvo primero con las Madres de Plaza de Mayo en Buenos Aires y luego se vino a Córdoba y estuvo con Familiares. En su relato él sí da cuenta de haber estado al tanto de las discusiones que se daban en torno a la legitimidad de recibir la reparación, pero señaló que en Córdoba los organismos fueron respetuosos de la decisión individual de cada uno y luego, cuando hace referencia a la "Pensión Universal", que es una reparación por la que están reclamando los ex presos en la actualidad, dice que él adhiere porque "es una demanda colectiva que beneficia al grupo", pero que no demandaría al Estado 
por "secuelas", porque son consecuencias de una decisión y un riesgo que él tomo voluntariamente. En estas declaraciones se ve por un lado como lo colectivo incide en las decisiones individuales y como en el negarse a demandar al estado actúa la moral revolucionaria a la que hacíamos referencia más arriba.

Por otra parte, para algunos la decisión de "recibir" estuvo enmarcada en las disputas de los Organismos de Derechos Humanos, en donde, como ya señalé, en ciertos sectores "la fuerza de la cosa dada" por el Estado, tomando la expresión de Mauss (1974), obliga a quien la recibe a restituirla de algún modo. Frente a esto, quienes optaron por "recibir" debieron resignificar las construcciones que habían hecho los Organismos que condenaron el cobro, al considerar que aceptar el dinero implicaba entregar a cambio la lucha.

Al principio yo no sabía si estaba bien cobrarla, había compañeros que se oponían, creían que era traicionarnos, vendernos al capitalismo, pero hablando con una abogada me dijo que lo viera diferente, que con esta medida el Estado no solo estaba pagando por habernos detenido tantos años ilegalmente, sino que implicaba que el Estado reconociera como Estado lo que había hecho y era una forma de reconocer el Terrorismo de Estado [...] creo que fue un gesto... pero no una reparación, el dinero en lo personal si me sirvió en un momento en que no estábamos pasando una buena situación económica y con eso pudimos enterar para compararnos la casa, pero no nos reparó nada, eso lo tuve claro, y anqué lo recibí nunca deje de reclamar y luchar para que se hiciera justicia (NORMA, octubre 2011).

Así en las opiniones de Norma se ve la presencia y la tensión con la postura publica y colectiva de los Organismos de rechazar la medida, la cual a nivel individual le generó dudas, pero finalmente a partir de necesidades individuales y de la opinión de la abogada encontró los argumentos necesarios para legitimar la decisión de aceptar el cobro. Se ven en este acto como actúan las diferentes fuerzas sociales, en la cual la decisión de Norma se aproxima a la postura de los Organismos en su conjunto que coinciden más allá 
de sus diferencias en el pedido de justicia hacia el Estado y desde un nivel individual justifica la decisión de cobrar desde una necesidad donde el dinero no "repara" los daños ocasionados, pero sirve para aliviar una situación personal adversa.

Yo para esa época estaba en Familiares, recuerdo que la Hebe fue muy dura con nosotros, con los ex presos que íbamos a cobrar, nos criticó mucho, pero acá en Córdoba la mayoría lo cobramos, yo lo use para comprar una casa para mis padres, que ya eran viejitos y alquilaban con dificultad y recuerdo que Emi15, cuando salió la reparación para los familiares de desaparecidos me llamo para preguntarme qué hacía y yo le dije que nosotros la mayoría habíamos cobrado y a quienes nos alcanzo lo invertimos en techo. (SARA, Noviembre 2011) A mí no me reparó nada, porque yo estaba trabajando y ese año me fui al sur, y estaba mi hijo que necesitaba ayuda, y yo tenía que cobrar supuestamente 90 mil pesos, eso sí lo sé, que lo tendría que haber cobrado ahora, en el año 2000 más o menos, para que fueran 90 mil, pero como mi hijo quería comprarse una empresita de minibuses se lo di a él, pero yo no cobré nada, 28 mil pesos cobré de los 90 mil que me correspondían y además al poco tiempo la empresita se fundió. (ROSA, Noviembre 2011).

El relato de Sara da cuenta en la decisión de cobrar el dinero están ligadas cuestiones políticas y personales y evidencia cómo la organización de la que participa funciona de marco para compartir con otras personas experiencias similares. Por otra parte, se ve que el dinero, en lo personal, necesita ser cambiado por otra cosa, necesita tener otro significado que lo haga tolerable, le restituya una utilidad y para muchos, esto se logró llevando la circulación de dones al ámbito de lo familiar, "lo invertimos en techo", "compre una casita", " ayudé a mi hijo", es decir, se saco al dinero de la moral de lo económico, para introducirlo en la moral del don, donde la fuerza de la cosa dada, y la obligación de devolver se traslada a otro donatario en el ámbito familiar (con quien usualmente se sienten en deuda por los daños ocasionados por su decisión de militar). 


\section{Reparaciones a víctimas de desapariciones forzadas y sus sucesores}

En el año 1994 se sancionó la ley $24.411^{16}$ que otorgó una reparación económica a las víctimas de desaparición forzada y a los sucesores de personas asesinadas por los militares, miembros de las fuerzas de seguridad o grupos paramilitares.

Esta ley fue la que generó la mayor discusión sobre lo que significaba reparar económicamente los crímenes de la dictadura, aun sin castigo. Para entender los conflictos y debates que suscitó esta medida es necesario remitirse a las dificultades que desató la desaparición forzada de personas, "con la negación de la información acerca de las víctimas durante la dictadura, la falta de respuestas individualizadas desde el restablecimiento de la democracia y la impunidad de los responsables" (GUEMBE, 2004, p. 16).

Los debates en torno a esta reparación, en su mayoría no fueron discutidos públicamente, las mayores discusiones por parte de los organismos de derechos humanos integrados por afectados directos (Madres, Abuelas y Familiares) giró en torno al temor de que el Estado estuviera entregando dinero a cambio del silencio sobre los hechos o la impunidad de los responsables. Por ello, se insistió constantemente que se dejara claro que el Estado debía esas respuestas.

Basado en ese temor, se exigió que las victimas de desaparición forzada fueran declaradas legalmente desaparecidos, y no muertos, y que cualquier tipo de reparación económica otorgada por el Estado fuera dado a nombre de las propias víctimas y no de sus sucesores legales. La importancia de esto radica en que la declaración por parte del Estado de que la persona continúa desaparecida, implica un reconocimiento oficial y la asunción de que el cuerpo no ha sido recuperado y de que no se sabe cuál fue el destino final. A partir de este reclamo, se realizó un nuevo estatus legal en el ordenamiento jurídico argentino para las personas que fue el de "ausente por desaparición forzada", y que vino a dar respuestas no solo al trámite para el cobro del beneficio económico que el Estado iba a entregar, sino para todos los trámites legales que tuvieran que hacer los familiares y no habían podido hacer hasta ese momento. 
A partir de entender que en el ámbito internacional se exigía a los Estados la compensación económica a las víctimas de graves violaciones a los derechos humanos, entre otras obligaciones, fue posible incorporar este reclamo junto a los de verdad y justicia. La mayoría de los organismos de derechos humanos comprendieron así que la reparación económica era una demanda legítima a la que el Estado debía responder.

Solo un grupo dentro los organismos, la Asociación Madres de Plaza de Mayo, liderado por Hebe Pastor de Bonafini, que había confrontado desde el inició con esta idea, mantuvo su oposición, para ella "Implicaba cambiar la vida de los desaparecidos y resignar el reclamo de justicia por una suma de dinero". Esta postura de rechazo, cobró dimensión pública, a través del órgano de prensa de la Asociación "El Diario de las Madres" y en el periódico de tirada nacional Pagina 12, que hizo eco de este debate. La postura cobro visibilidad y contribuyó a legitimar socialmente el trabajo que venían realizando las madres, y al mismo tiempo por la posición que ocupa la Asociación de Madres de plaza de Mayo en el mapa de los Organismos donde Hebe es una de las voces más legitimadas para hablar y sentar posición en materia de la lucha por los derechos humanos, llevo a que quienes están de acuerdo con recibir el pago debieran justificar su accionar frente a las acusaciones de "que quienes reciben el dinero se prostituyen".

Cabe señalar que este debate público en torno a la pertinencia o no de cobro y el alcance de las sanciones morales, se concentró en Buenos Aires y en aquellos lugares donde la Asociación de Madres tuviera mayor influencia simbólica. En el caso de Córdoba, donde no existe la Asociación de Madres y los padres de desaparecidos se nuclean en Familiares, si bien se consultaron entre sí a la hora de recibir la reparación económica, públicamente no tomaron posición, se dijo que a nivel individual cada uno tenía razones suficientemente validas para aceptar o rechazar el cobro.

$\mathrm{Al}$ respecto Emilia recuerda:

Cuando salió la reparación, yo no sabía qué hacer, lo consulte con Sara \{Ex presa política, que integraba Familiares y que había cobrado la reparación $\}$ y ella me dijo que la mayoría la 
Moral y don en las reparaciones económicas...

había cobrado. Así que reuní a mis hijos y decidimos entre todos aceptarlo, pero yo les puse la condición de que fuera para techo, no viajes ni nada de eso. Que fuera útil a una necesidad y no al placer (EMILIA, familiar de desaparecido, Noviembre, 2011).

Aquí nuevamente se muestra como la decisión se articula entre lo individual y lo colectivo, pero al mismo tiempo para ser aceptado el dinero debe ser sacado de la moral del cálculo, el interés y el disfrute para ser introducida en la moral del don y específicamente en el ámbito familiar.

\section{Intercambio, Obligaciones y valores morales}

Toda relación social conlleva obligaciones, es decir, deberes que los individuos sienten poseer en su relación con otros individuos. La existencia y el cumplimiento de estas obligaciones sociales vinculan a los individuos entre sí. La vida social implica una permanente circulación de cosas. (MAUSS, 1979; SIGAUD, 2004). Como planteaba Mauss en su clásico "Ensayo sobre el don" [...] lo que se intercambia no son exclusivamente bienes o riquezas, muebles e inmuebles, cosas útiles económicamente; son sobre todo gentilezas, festines, ritos, servicios militares, mujeres, niños, danzas, ferias en las que el mercado ocupa sólo uno de los términos de un contrato mucho más general y permanente" (1979, p. 160).

Las personas participan de un constante intercambio y al hacerlo están obligados a cumplir con determinadas pautas. Por ello y considerando que el intercambio constituye la punta del iceberg de las relaciones sociales, a las cuales expresa, es que podemos decir que el intercambio interesa más por lo que muestra del mundo social que por lo que es en sí. En otras palabras, al hablar de intercambio nos importa ver quiénes intervienen, qué es lo que se da, qué es lo que se devuelve.

Por eso, el análisis de las reparaciones permite poner en foco en las controversias suscitadas a partir de las obligaciones (reales o percibidas) que son producto de las relaciones establecidas entre 
las victimas/ciudadanas de derecho, los diferentes colectivos de derechos humanos y el estado.

Si analizamos los comportamientos a la luz del marco más amplio de relaciones sociales en el que están insertos los actores, podremos observar que determinadas conductas sólo se explican por la existencia de relaciones (sostenidas en el intercambio) que atrapan a los individuos en un circuito de deudas y favores, donde valores morales dan cuenta de las obligaciones que se deben cumplir so pena de romper la relación ${ }^{17}$. Faltar a las obligaciones es señal de que algo está sucediendo en ese vínculo.

Al decir de Mauss (1979), el don instituye una doble relación entre el que dona y el que recibe: por un lado, una relación de solidaridad en la medida en que el acto de compartir aproxima a las personas, por el otro, una relación de superioridad, ya que aquél que recibe un don contrae en ese mismo acto una deuda con quien donó, convirtiéndose el primero en deudor del segundo -; esta idea es la que considero subyace en la decisión de rechazar las reparaciones económicas principalmente por parte de las Asociación Madres de Plaza de Mayo, que creen que en el acto de "no recibir" evitan someterse al estado, esto lo podemos observar en las palabras que expresó públicamente Hebe Bonafini quien dijo que "quien cobra la reparación económica se prostituye" y que recibir dinero significa "vender la sangre de nuestros hijos".

Consideran que "la fuerza de la cosa dada" por el Estado, tomando la expresión de Mauss (1979), obliga a quien la recibe a restituirla de algún modo. Estas posiciones muestran diferencias políticas sustanciales y explícitas con el resto del movimiento de derechos humanos ya que argumentan que condenan el cobro porque consideran que recibir el dinero (don) implica entregar a cambio la lucha (contradon). Con lo cual la relación social creada por el don estaría expresada en la deuda, que implica "recibir", en este sentido el reconocimiento de la misma conlleva a entrar en la lógica de la retribución de dones, en un círculo de relaciones de intercambio en el que están inmersos los actores.

$\mathrm{Al}$ analizar el acto de donar como un encadenamiento de tres obligaciones (dar, recibir y devolver) una de las preguntas que 
Moral y don en las reparaciones económicas...

Mauss se hacía era ¿por qué se dona? La respuesta se encontraba en el hecho de que:

Donar, obliga: [...] tanto negarse a dar, como olvidarse de invitar o negarse a aceptar, equivale a declarar la guerra, pues es negar la alianza y la comunión. Se da porque se está forzado a dar, ya que el donatario goza de una especie de derecho de propiedad sobre todo lo que pertenece a quien recibe. Esta propiedad se manifiesta y se concibe como una especie de lazo espiritual. (1979, p. 169-170).

Para entender la circulación del don y contradon en este caso y como juega la opción de recibir o no recibir, no debemos olvidar que ese acto supuestamente desinteresado de donar pero sin embargo "obligatorio e interesado" (MAUSS, op.cit.) funciona para quien dona como fuente de prestigio "[...] el poseedor de objetos valiosos gana mérito y prestigio fundamentalmente gracias a la publicidad que obtiene desembarazándose de ellos" (LEACH, 1996, p. 163)

En el caso de las reparaciones el por qué de la donación que realiza el estado está impulsada por las obligaciones para con un tercero, por el interés en cumplir con las obligaciones impuestas por la CIDH con el fin de mantener las relaciones con la OEA.

Aquí el intercambio y la circulación de dones se puede leer en diferentes niveles, por una parte el Estado argentino al cumplir con las exigencias de la OEA, establece una alianza, con la que espera abrir y mantener la circulación de dones y los beneficios que significa la comunión con este organismo internacional. Es decir que la reparación económica (don) se da con el interés de mantener una relación social, en este caso entre el estado y un ente supranacional.

En un segundo nivel, el estado con las reparaciones económicas, obliga a quienes lo reciben a renunciar (contradon) a entablar acciones judiciales por daños y perjuicios por los hechos cometidos por el terrorismo de estado y espera que las victimas (en un contexto de impunidad por esos crímenes) reconozcan al estado, que han sido reparados al menos en lo económico. 


\section{La obligación de devolver}

Ahora bien, Mauss también - y fundamentalmente - se preguntaba por la obligación de devolver. Para ello apelaba - recurriendo al derecho maorí - a la existencia de un espíritu de la cosa que obliga a que ésta vuelva a su donante: "el regalo recibido, cambiado y obligado no es algo inerte. Aunque el donante lo abandone, le pertenece siempre. Tiene fuerza sobre el beneficiario del mismo modo que el propietario la tiene sobre el ladrón [...] el hau acompaña a la cosa, quien quiera que sea su detentador" (1979, p. 167).

Ahora bien, si partimos de la idea de que las relaciones sociales implican derechos y obligaciones y que el intercambio es el modo en el que se expresan las mismas, podríamos sostener - al igual que Sigaud- que al faltar a una obligación - la de devolver- se corre el riego de romper el vínculo que me une a esa persona, esa "especie de lazo espiritual"rs.

Como planteé en párrafos anteriores, los actores, si bien atrapados en la dinámica de esas relaciones ${ }^{19}$, tienen un claro interés en la continuidad de las mismas " $[. .$.$] el interés de las dos partes$ en recrear las relaciones de intercambio es la principal garantía del futuro de esas relaciones, más que cualquier tipo de garantía" (SIGAUD, 1996, p. 8)

Como plantea Leach (1996), el intercambio de regalos (en el caso planteado aquí lo que circulan son reparaciones dinero, reconocimiento ${ }^{20}$ y legitimación) en realidad es lo que uno ve, pero lo que subyace y condiciona el acto de recibir o no estas reparaciones económicas, es el sentimiento de deuda que se generaría con el donante al "recibir" y para algunos individuos y organismos significa como dijimos anteriormente renunciar a la lucha ya que consideran que el aceptar implica renunciar a la demanda de verdad y justicia, es decir, lo que genera conflicto es el peso de las obligaciones morales de "devolver".

Así el "no recibir" de algunas víctimas tiene como objetivo evitar que la deuda - generada "por la fuerza de la cosa dada" creé una situación de dependencia con el estado y de este modo sentirse libres de la "obligación moral de devolver" conservando la 
autonomía para seguir reclamando por una reparación integra que incluya de manera incondicional la "verdad y justicia".

En tanto que para quienes aceptaron el resarcimiento económico implica la renuncia a hacer reclamos futuros al Estado por daños y perjuicios, aunque muchos de ellos señalen que aceptaron el dinero porque creen que es un derecho y no se sintieron, ni se sienten obligados a entregar "la lucha" a cambio, porque no creen que la reparación económica en verdad haya reparado.

En el sistema de don, el desinterés del donante es la condición de su prestigio. "Sin embargo, los dones vuelven, son recíprocos, son necesariamente devueltos. La obligación de devolver parece desmentir la gratuidad de los dones. La gratuidad, por tanto, sería aparente, una ficción, una mentira social, la máscara de un intercambio interesado. Además, si se pierde prestigio al recibir, ese prestigio se convierte en tenencia. (DOMINIQUE, 2003, p. 22).

En este sentido, aquello que Mauss plantea como fuente de reconocimiento social - dar-, aquí debemos traducirlo en términos de reconocimiento en dos planos: el primero, puede representarse hacia el interior en relación con los organismos de Derechos Humanos y el segundo, hacia el exterior del espacio de relaciones que procura el Estado con los organismos internacionales.

Profundizando este planteo el interés del estado en dar una reparación económicamente a las víctimas, está motivado por el compromiso asumido ante la CIDH y cuyo cumplimiento habilita la recreación de la relación con la OEA, lo que implica la circulación de bienes y beneficios resultantes de esta relación.

Desde un segundo nivel, el Estado como donante expresa en el Fundamento de Ley que la medida "tiene una finalidad reparadora de situaciones injustas, propias de la concepción absolutista y excluyente de todo disenso que imperó en esa etapa $[. . .]^{21}$ en tal sentido, el senador Marín, autor del proyecto de ley y miembro de la comisión informante, aclaró que la finalidad perseguida era "[...] hacer justicia a todos aquellos que sufrieron una detención ilegal”, mientras que el senador Brasesco, por su parte, también resaltó que 
"el bien jurídico tutelado por el proyecto es la libertad del hombre, la dignidad del ser humano y que "en nombre de esa dignidad del ser humano, de esa reparación histórica, hombres de las distintas bancadas, inclusive con interpretaciones distintas sobre el proceso que vivimos, llegamos a este proyecto [...]" (DIARIO DE SESIONES DEL SENADO, 30 de Noviembre de 1991, p. 3387 y 3389, respectivamente).

Aquí el interés manifiesto mantiene en apariencia el espíritu de gratuidad del don pero al exigir como contraparte la renuncia a futuros reclamos por daños y perjuicios plantea además de la renuncia, la aceptación y el reconocimiento de que al menos en el plano económico el estado ha dado justicia a las víctimas.

\section{Disputas públicas y valores morales}

Hasta aquí he señalado las reparaciones económicas que se otorgaron durante la década de los 90, y he hecho referencia a como los diferentes colectivos de victimas de terrorismo de estado han resinificado la medida en un entrecruzamiento entre lo individual y lo colectivo y como al mismo tiempo las experiencias han sido diversas en la Capital y en el interior, pero me interesa profundizar un poco más sobre el tratamiento publico de estas disputas morales y los actores que intervienen en él.

Como bien señala (JELIN, 1998) en un primer momento fueron los vínculos primordiales los que impulsaron a los familiares a salir de la esfera privada y realizar acciones públicas de reclamo. Tal es así, que a partir de la última dictadura militar, los organismos de Derechos Humanos en Argentina, adquieren denominaciones centradas en lo familiar (Madres de Plaza de Mayo, luego las Abuelas, los Familiares de desaparecidos y detenidos por razones políticas), es este aspecto el de "lo familiar" lo que aparece como un criterio central para la legitimidad de esta lucha ya que esta se centraría en la lógica de lo afectivo -recuperar al pariente desaparecido- antes que en lo político. En el plano de la justicia, también este vínculo es condición necesaria para realizar reclamos ya que legalmente 
son sólo los familiares los que están en condiciones de efectuar las demandas reparatorias y sólo a nivel personal o individual.

Si bien, en términos legales la decisión de cobrar es una cuestión individual, las políticas de reparación generaron grandes disputas en el debate público, ya que el peso del discurso de oposición de algunas personas de relevancia dentro de los Organismos, llevo a que en términos políticos las opciones se vieran condicionadas y la decisión de aceptar o no estuviera atravesada por procesos colectivos.

En este sentido, las posturas de los organismos respecto a las reparaciones han sido diversas y han estado atravesadas por la articulación de lo publico y lo privado, lo singular y lo colectivo, lo local y lo nacional, pero en líneas generales podemos decir que en Buenos Aires, principalmente en La Capital las posturas de los organismos se dividieron entre quienes condenan el cobro (Asociación Madres de Plaza de Mayo, Asociación de Ex Detenidos Desaparecidos) y aquellos que no (Madres Línea Fundadora, Abuelas de Plaza de mayo, Familiares de Detenidos Desaparecidos, H.I.J.O.S.), mientras que en la periferia no se dio igual y en el caso especifico de la ciudad de Córdoba ningún organismo se opuso públicamente al cobro de las reparaciones.

Las disputas públicas en torno a las reparaciones económicas, estuvieron centradas en torno al rechazo de que la vida (o muerte) de un familiar pueda ser cotizada en dinero. El aporte de Bourdieu (1997) ayuda a entender este planteamiento, ya que señala que el precio, elemento característico por excelencia de los intercambios en la economía de mercado, sería inapropiado para repara en este caso, ya que se constituye en un tabú para intercambios donde interviene la moral, la vida y la muerte, en tanto pertenecen a "la economía de las cosas que no tienen precio".

Una de las principales representantes de esta postura, como ya he señalado fue la Asociación Madres de Plaza de Mayo, que tanto en actos públicos como en diferentes medios de comunicación sentó su posición, señalando que "los que cobran las reparaciones económicas se prostituyen". Así, durante una “toma simbólica de la bolsa de comercio"22 la presidenta de esta asociación, Hebe de Bonafini, manifestó: 
Es inmoral que la sangre de nuestros hijos pretenda ser cotizada aquí, en el mismo lugar en el cual los traficantes le ponen precio a la vida y a los sufrimientos de nuestro pueblo [...] Con estos Bocones quieren 'resarcirnos' por los crímenes que los militares, los empresarios, los políticos, los burócratas sindicales y la iglesia cometieron contra nuestros hijos. Muchos de los llamados "Organismos de Derechos Humanos", muchos familiares de desaparecidos y los partidos políticos, están haciendo fila para cobrar. Ellos calculan por anticipado la cotización de la sangre de los revolucionarios. Los que se prostituyen se olvidan que nuestros hijos - los 30000 desaparecidos- se oponían a este capitalismo asesino que se exhibe en la Bolsa de Comercio. [...] ("Las Madres en la Bolsa de Comercio" DIARIO DE LAS MADRES; ${ }^{\circ}$ 145; Setiembre de 1997).

Este fragmento permite visualizar que lo que se puso en cuestión con las reparaciones económicas fue el "valor de la vida" ya que para quienes se oponen al cobro pensar la vida dentro de la moral del dinero, "cotizar la sangre", ponerle un "precio a la vida" es introducirla en la institución del mercado y como tal es un acto "inmoral", ya que es visto como una negociación, en la cual, en términos de Mauss lo que se estaría sancionado es este tipo de intercambio de vida-dinero.

En este sentido, el "No aceptamos que se le ponga precio a la vida" se constituyó en una de las consignas políticas de la Asociación Madres de Plaza de Mayo, que expresan en su página web:

No aceptamos que se le ponga precio a la vida. Nuestros hijos nos enseñaron el valor que tiene la vida. Ellos la pusieron al servicio de todos los oprimidos, de los que sufren injusticias. Las Madres de Plaza de Mayo rechazamos la reparación económica y decimos que la vida sólo vale vida. Que la vida sólo vale algo cuando la ponemos al servicio del otro. La vida de un ser humano no puede valer dinero y, mucho menos, la vida de un revolucionario. Lo que hay que reparar con justicia no se puede reparar con dinero. Los radicales y menemistas que perdonaron a los asesinos, ahora quieren 
tapar sus crímenes con dinero. Nadie le va a poner precio a la vida de nuestros hijos. Las Madres de Plaza de Mayo seguiremos afirmando que los que cobran las reparaciones económicas se prostituyen. (DOCUMENTO, "Nuestras consignas", Diciembre del 2005).

En estas afirmaciones se sanciona moralmente la decisión de cobrar como un acto de "prostitución", en el cual la vida (o la justicia por la muerte) es intercambiada por dinero y al tener un precio y cotizarse en un mercado, la vida se incorporaría a la esfera de lo impersonal ya que al entrar en juego el dinero, cancelaría la "fuerza" que obliga a ser restituida por otros medios, en este caso por el juicio y castigo a los culpables.

Pero al mismo tiempo se sanciona la postura del estado de pretender "reparar con dinero" lo que solo se puede "reparar con justicia”, esta reprobación de la política de reparación económica del estado, también es leída en clave de estas dos morales antagónicas que son la de la revolucionaria en donde "la vida solo vale vida", "la vida vale cuando es puesta al servicio de otro", "al servicio de todos los oprimidos", "de los que sufren injusticias" en oposición a una moral capitalista, donde "los militares, los empresarios, los políticos, los burócratas sindicales y la iglesia "quieren tapar sus crímenes con dinero".

Si bien el antagonismo entre estas dos morales que cobra visibilidad mayor a partir de la promulgación de estas leyes de reparación, estas disputas se han manifestado en otras oportunidades en donde se articula la noción de vida, derechos humanos y política. Para las Madres de Plaza de Mayo, la consigna de "rechazo a las reparaciones económicas", define su identidad (la cual, como ya señalé, es expresada como una de sus consignas políticas) y es constituyente de su posicionamiento y legitimidad en la esfera publica. La defensa de la moral revolucionaria ha guiado las acciones de las Madres de Plaza de Mayo desde sus comienzos, en su accionar expresan una concepción moral del mundo que entra en conflicto con otras concepciones morales, específicamente con la del mercado, tal es así que durante la visita realizada por Las Madres durante la Asamblea general de la OEA en 1980, para pedir que este organismo sancionara 
a la Dictadura Argentina en base a los resultados del informe que había elaborado la CIDH en su vista a este país, Hebe de Bonafini y Nora Cortiñas al ser reporteadas por un periodista acerca de cómo veían la marcha de las deliberaciones y el manejo del problema de los derechos humanos en la Asamblea, respondieron:

Como Comisión de Madres de Plaza de Mayo tenemos gran esperanza, pero como madres nos sentimos muy mal dentro de estos pasillos donde vemos que los seres humanos son comerciados por trigo, por dinero por petróleo. [...] escuchábamos de que tal o cual país cambiaba su voto por negocios, Eran momentos de decepción muy profunda" (DENUNCIA, diciembre 1980).

La “decepción” expresada por las madres da cuenta una vez más de lo irreconciliable de articular la esfera de la vida y los derechos humanos con la esfera del mercado, de los "negocios", donde la vida pueden ser rebajada, considerada como un bien que al igual que el trigo, el dinero y el petróleo pueden ser intercambiados entre sí.

Esta idea y la crítica a articular estas dos esfera se ha manifestado en diferentes momentos, a lo largo del tiempo, marca un posicionamiento y es uno de los ejes que refuerza la legitimidad de la Asociación dentro del mapa de los organismos. Legitimidad que hace que las opiniones de su presidenta, Bonafini, sean valoradas al punto de influir en las decisiones personales y de los otros organismos, que para aceptar las reparaciones, muchas veces se sintieron obligados a contrarrestar la sanción moral impuesta desde la Asociación.

Un ejemplo de esto, aparece en el diario Página 12, donde el diario hace eco de las disputas en torno a las reparaciones: Hebe de Bonafini defiende la consigna de Las Madres en su columna "La vida solo vale vida" (en el cual expone los argumentos que he señalado en párrafos anteriores), mientras que Marta Dillon de hijos disiente y explica las razones de quienes aceptarán la reparación ofrecida en una columna titulada "Tenemos derecho a ese dinero":

[...] Es dinero, nada más. Que nunca alcanzará para silenciar el pedido de juicio y castigo. Que no nos hará olvidar 
ni perdonar. El dinero no repara la ausencia, no borra la historia, no empaña los ideales de los caídos. Hay quienes eligen cobrarlo y quiénes no. Cada uno tiene argumentos suficientes - y respetables - para hacerlo o no.

[...] ese insulto que llevaba por firma el logotipo de la Asociación Madres de Plaza de Mayo parece querer sentar una moral universal [...] Semejante declaración colgada de los árboles suena demasiado a expulsión.

En los secuestros que perpetraban las fuerzas de seguridad no sólo se llevaban a la gente. También les quitaron sus bienes y entre otras cosas mil veces más importantes - como su vida y su proyecto de una sociedad justa - la posibilidad de dejar una herencia para sus hijos. La reparación económica no repara [...] Ya no nos devolverán a los desaparecidos. Esa es la verdadera injusticia. Tenemos derecho a ese dinero. Y seguro que sería fantástico poder rechazarlo, decir la verdad, que la vida de nuestros familiares no tiene precio y dar vuelta la cara a los pobres valores de este mundo. Pero muchos no podemos. No queremos. Necesitamos la guita [...]

Es muy respetable que ella se fije sus límites. Pero son los suyos. La vara de la ética no le pertenece. [...] Cuando me toque el turno de recibir ese dinero mi hija sabrá que la casa en que vivimos es nuestra porque su abuela desaparecida nos ayudó [...] ("La polémica de las reparaciones" DIARIO PÁGINA 12, 13 diciembre de 1998).

Aquí, Dillon va desarticulando uno a uno los argumentos de sanción moral al cobro, en primer lugar alude a que la reparación económica no repara, diciendo que "es dinero nada más", que no implica silenciar el pedido de justicia, "ni repara la ausencia”, ni traiciona los valores revolucionarios.

En segundo lugar, critica la moral única y el insulto en relación a la acusación de que "quien cobra la reparación se prostituye" y la pretensión por parte de Madres de Plaza de Mayo - puntualizándolo en la persona de Hebe de Bonafini - de sentar una moral universal, señalando que "la vara de la ética no le pertenece".

Por último, justifica el cobro como una necesidad y un derecho. "Un derecho" en el cual el Estado reconoce su responsabilidad por 
haber quitado vidas, el proyecto de una sociedad justa y la posibilidad de dejar una herencia para sus hijos y que si bien no repara en tanto "no devolverá a los desaparecidos" sí permite cubrir necesidades económicas originadas en ese daño.

Sin embargo, señala que le gustaría poder rechazarla y dar vuelta la cara "a los valores de este mundo" pero que la necesidad hace que las decisiones sean otras y al igual que la mayoría de quienes recibieron la reparación dice que cuando la cobre, le dirá a su hija que la casa donde viven les pertenece porque su abuela desaparecida, las ayudo, es decir, introduce la reparación en la moral del don, en el ámbito de lo familiar. Esto da muestra también, de que la oposición entre estas dos morales y la reprobación de articular estas dos esferas sigue operando y teniendo peso en las decisiones individuales y colectivas de los grupos, aun de aquellos que expresan estar a favor del cobro y del respeto a la decisión de quienes así lo decidan.

Fuera de estos debates públicos de los que he intentado dar cuenta, el resto de los organismos de derechos humanos, no se pronunciaron públicamente, y dejaron librada a la voluntad de los familiares y víctimas el cobro o no de los llamados "beneficios". Por lo que cada individuo o grupo familiar tramitó de manera privada y silenciosa, aquello que en teoría quería simbolizar el reconocimiento estatal de un daño.

\section{Consideraciones finales}

Las relaciones y obligaciones sociales de las que he intentado dar cuenta a lo largo del artículo están inscriptas en una configuración sociohistórica determinada. Como planteé al comienzo, el hecho de que las reparaciones económicas se hayan implementado en el periodo de transición democrática, en un contexto de impunidad donde estaban vigentes las leyes de Obediencia Debida y Punto Final otorgaron una particular lectura al significado del dinero como reparador.

Pensar en términos de configuraciones permite indagar acerca de la autonomía y la dependencia relativa de los hombres y los grupos en sus relaciones, evitando, de esta manera, aislar las conductas, 
al analizarlas dentro de sus cadenas de interdependencias recíprocas. Mauss al respecto señala que "No son los individuos, sino las colectividades las que se obligan mutuamente, las que cambian y contratan; las personas que están presentes en el contrato son personas morales" (1979, p. 159-160).

En ese sentido para el análisis del las reparaciones económicas que tuvieron lugar durante la década del 90 ha sido preciso considerar las particularidades de la experiencia individual (las militancias, el daño sufrido) atravesadas por todas esas "otras" relaciones surgidas del espacio social y político general y del campo de los Derechos Humanos, que se encuentran regidas por "normas y valores particulares". No hablamos de hombres individuales sino de sujetos que pertenecen a determinados grupos y que poseen intereses e identidades compartidas.

Las redes de interdependencia otorgan una fuerza particular a las acciones de los sujetos y, a su vez, les marcan límites estrictos. Entonces hablar en términos de configuraciones sociales en conjunción con la lógica de los intereses que sustentan los individuos, permite dar cuenta de las estrategias desplegadas por lo sujetos en el manejo de la "deuda", estrategias que, como se sostuvo en párrafos anteriores, permiten flexibilizar el mundo social del que forman parte.

Así en el contexto de lo grupal y la militancia es donde se dan los debates de carácter moral en torno a la legitimidad o no de recibir de las "indemnizaciones" o "beneficios".

En las decisiones individuales, en su mayoría eso no sucedió, se aceptó sin cuestionamientos, aunque de los relatos se desprende que el "recibir" estaba enmarcado en una situación de necesidad y se pone en cuestionamiento el "espíritu" del "donante" ya que consideran que el resarcimiento económico no reparó, y que nunca tuvo ese espíritu.

Por otra parte, la violencia, la economía y la moral parecen estar en el centro de los principios reguladores de la política en las sociedades. Nuestro caso de análisis toca varios puntos significativos con respecto a esta afirmación ya que vincula representaciones opuestas en las concepciones morales de nuestra sociedad. La vida, la muerte y en consecuencia los Derechos Humanos, parecen ser por excelencia de la esfera de las "cosas que no tienen precio", sin 
embargo, en un sistema donde lo económico tiene una relevancia central entran en el orden de las cosas que pueden ser compensadas con dinero. Este caso revela que, pese a la conformación del mercado y la economía de precios como principios reguladores de nuestra economía, no todos los intercambios en nuestra sociedad están regidos por la "moral del mercader" como dijera Mauss.

Como hemos visto en la perspectiva de los actores el intercambio vida-muerte/dinero, desata conflictividades en la definición de las representaciones sobre estos objetos sociales, y genera relaciones sociales y políticas que provocan fusiones y fisiones (EVANS PRITCHARD, 1977) entre grupos e individuos, tanto en colectivos altamente institucionalizados como los Estados, como entre grupos políticos e incluso en los que parecen estar por fuera de toda lógica política y económica como los grupos familiares.

Las reparaciones económicas, en tanto ejemplo de situaciones sociales - preñadas de valores sociales - permite preguntarnos acerca de la "politicidad" e "institucionalidad" de los comportamientos políticos de la sociedad frente a los genocidios y sus consecuencias. Ante los cuales, los Estados Modernos, erigidos como garantes de la pacificación social han tenido que implementar políticas para "reparar" las violaciones a los derechos humanos, frente a hechos que en nuestras representaciones aparecen como irreparables. Ante estos intentos reparatorios en cada contexto social e histórico surgen nuevas concepciones acerca de su valor, se generan nuevos intercambios y nuevas racionalidades, de esto he intentado dar cuenta a partir de la perspectiva de los actores.

\section{MORAL AND GIFT ON THE ECONOMIC REPAIR TO VICTIMS OF STATE TERRORISM IN ARGENTINA}

Abstract: This article analyzes the economic reparations that implemented the Argentine state against their crimes committed during the military dictatorship (1976-1983) and the values and attitudes that make up the victims and families in reply to the claims that the State proposes as a form of reparation. I believe that analyzing these repairs in the light of the theory of The Gift of Marcel Mauss, can bring light on this social fact and ethical and political debates that have arisen. Keywords: Economic reparations. Moral. Gift. Military dictatorship. Argentina. 


\section{Notas}

${ }^{1}$ Estos grupos pueden ser enumerados cronológicamente por su aparición en el ámbito público: la Liga Argentina por los Derechos del Hombre (1937), el Servicio Paz y Justicia (1974), la Asamblea Permanente por los DDHH (1975), el Movimiento Ecuménico por los DDHH (1976), Familiares de Detenidos y Desaparecidos por Razones Políticas (1976), Madres de Plaza de Mayo y Abuelas de Plaza de Mayo (1977), la Asociación de Ex Detenidos Desaparecidos (1984), Correpi (1992), Cofavi (1992), Memoria Activa (1994) e H.I.J.O.S. (1995). (DA SILVA CATELA, 2001).

${ }^{2}$ Decreto del PEN No 157 del 15 de diciembre de 1983.

${ }^{3}$ Por decreto del PEN se dispuso el sometimiento a juicio de los miembros de las tres primeras juntas militares. La Cámara Federal en lo Criminal y Correccional de la Capital Federal dictó sentencia el 9 de diciembre de 1985. Esta histórica resolución estableció que había existido un plan deliberado y concertado para ejecutar una política de represión encubierta y que esa política se convirtió en el arma principal de la dictadura en su campaña para eliminar a la subversión. Como resultado del proceso se condenó a cinco de los comandantes de las juntas militares por los delitos de homicidios, privaciones ilegítimas de la libertad y torturas, entre otros. Cuatro de los comandantes fueron absueltos porque la evidencia en su contra resultaba insuficiente e inconclusa.

${ }^{4}$ Se trató de la ley 23.466 del año 1986 sancionada el 30 de octubre de 1986. Reglamentada por decreto No 1228/87. Orientada a la implementación de pensiones a esposas e hijos de desaparecidos.

${ }^{5}$ En el año 1984, se dictó la ley 23.053 que dispuso el reingreso al cuadro permanente activo del servicio exterior de la nación, de los funcionarios declarados prescindibles durante la dictadura. En el mismo año se sancionó la ley 23.117, que estableció la reincorporación de los trabajadores de las empresas del Estado que hubieran sido cesanteados por causas políticas y gremiales durante dicho período. En el transcurso de 1985, la ley 23.238 dispuso la reincorporación y el reconocimiento del tiempo de inactividad a los efectos laborales y previsionales de los docentes que habían sido declarados prescindibles o cesantes por causas políticas, gremiales o conexas hasta el 9 de diciembre de 1983. Por su parte, la ley 23.523, dictaminó la reincorporación de los trabajadores bancarios despedidos por razones políticas. El 28 de septiembre de 1985 se dictó la ley 23.278 que se dirigió a aquellas personas que por motivos políticos o gremiales fueron dejadas cesantes, declaradas prescindibles o forzadas a renunciar a sus cargos públicos o privados, o se vieron obligadas a exiliarse. Estableció que el período de inactividad se computaría a los efectos jubilatorios.

Anos 90, Porto Alegre, v. 19, n. 35, p. 383-415, jul. 2012 
${ }^{6}$ El estado de sitio fue dictado el 6 de noviembre de 1974; en el mismo decreto el gobierno de María Estela Martínez, había ordenado la "eliminación de la subversión", lo que dio lugar al comienzo de la aplicación del terrorismo de Estado en Argentina.

${ }^{7}$ El 2 de octubre de 1992 la Comisión dictó el Informe 28/92 en el que dispuso: “1. Que las leyes Numero 23.492 y 23.521 y el Decreto no 1002/89 son incompatibles con el artículo XVIII (derecho de Justicia) de la Declaración Americana de los Derechos y Deberes del Hombre y los artículos 1, 8 y 25 de la Convención Americana sobre Derechos Humanos. 2. Recomienda que el Gobierno de Argentina otorgue a los peticionarios una justa compensación por las violaciones a las que se refiere el párrafo precedente. 3. Recomienda al Gobierno de Argentina la adopción de medidas necesarias para esclarecer los hechos e individualizar a los responsables de las violaciones de derechos humanos ocurridas durante la pasada dictadura militar. 4. Dispone la publicación del presente informe". CIDH, Informe No 28/92, casos 10.147, 10.181, 10.240, 10.262, 10.309 y 10.311 Argentina, dictado el 2 de octubre de 1992. Publicado en el Informe Anual de la CIDH 1992 - 1993; OEA/Ser.L/V/II.83; Doc. 14, 12 marzo 1993; Original: Español. htpp://www. oas.org A la recomendación de la CIDH de reparar económicamente se sumó al incipiente reclamo de las víctimas.

${ }^{8}$ Ley 23492, publicada en el Boletín Oficial el 29 de diciembre de 1986

${ }^{9}$ Ley 23521, publicada en el Boletín Oficial el 9 de junio de 1987.

${ }^{10}$ Decretos del No 1.002, 1.003, 1.004 y 1.005 publicados en el Boletín Oficial el 10 de octubre de 1989, y decretos No 2.741 al 2.746 del 29 de diciembre de 1990. ${ }^{11}$ Sancionada el 27 de noviembre de 1991, publicada en el Boletín Oficial el 2 de enero de 1992 con la observación efectuada en el decreto No 2722/91. Reglamentada por decreto No1023/92 modificado por decreto No 205/97. Ampliada por decreto $\mathrm{N}^{\circ} 1313 / 94$.

${ }^{12}$ Para quienes durante la detención sufrieron lesiones gravísimas, además de la indemnización reconocida por el número de días de detención, el monto del beneficio se incrementó en una suma equivalente al setenta por ciento de la establecida en caso de muerte.

${ }^{13}$ Cada bono tiene un valor nominal o de capital y a su vez paga un interés. Los bonos pueden ser canjeados en cualquier momento al precio que coticen en el mercado cambiario o pueden ser canjeados al Estado a su valor total al momento de su vencimiento. Los Bocones Proveedores Serie II vencen a los 16 años de su emisión.

${ }^{14}$ La Asociación de Ex Detenidos Desaparecidos nuclea a personas que estuvieron detenidas legal y clandestinamente durante la última dictadura militar y que luego lograron recuperar su libertad.

${ }^{15}$ Referente a nivel local de Familiares de Desaparecidos por Razones Políticas. 
${ }^{16}$ Sancionada el 7 de diciembre de 1994. Decreto reglamentario 403/95 sancionado el 29 de agosto de 1995.

${ }^{17}$ Faltar a las obligaciones es señal de que algo está sucediendo en ese vínculo. En una situación extrema esto puede implicar la ruptura de la relación.

${ }^{18}$ Con respecto al cumplimiento de las obligaciones por parte de los individuos que están trabados en una relación de intercambio, Leach sostiene que "[...] la tradición establece las normas de lo que es correcto. Pero el principio de sustitución hace posible que cualquier hombre evite cumplir la letra de sus obligaciones, si así lo elige; sin embargo, si un individuo no paga lo adecuado, pierde "cara" (prestigio) y corre el riesgo de una pérdida general de estatus de clase" (1996, p. 170)

${ }^{19}$ La relación en este caso es la de ciudadano- Estado. Con los derechos y obligaciones que a cada parte le corresponde - expresados fundamentalmente en la Constitución Nacional-.

${ }^{20}$ De la lucha de los organismos de DDHH en sí misma y por parte de estos hacia las políticas de Derechos Humanos desarrolladas por el estado

${ }^{21}$ Por medio de estas leyes, así como de otras posteriores complementarias, el Congreso Nacional, cumplió con el compromiso asumido por la República ante organismos internacionales encargados de velar por los derechos humanos y expresó su voluntad política de compensar, al menos económicamente, a las personas privadas injustamente de su libertad durante ese periodo.

\section{Referencias}

ARGENTINA. Decreto del PEN n. 157 del 15 de diciembre de 1983.

. Decretos n. 1.002, 1.003, 1.004 y 1.005. Boletín Oficial, 10 de octubre de 1989, y decretos n. 2.741 al 2.746 del 29 de diciembre de 1990.

. Ley 23.466, de 10 diciembre de 1986. Otorgamiento de pensiones no contributivas para el derechohabiente de las personas desaparecidas entre el 24/3/76 y el 9/12/88. Boletín Oficial, 16 de febrero de 1987.

. Ley 23.053, de 22 de febrero de 1984. Reincorporaciones de Personal del Servicio Exterior de la Nación declarados prescindibles. Boletín Oficial, 4 de abril de 1984.

. Ley 23.117, de 30 de septiembre de 1984. Incorporación de trabajadores despedidos o cesanteados de las empresas mixtas del Estado por razones políticas, gremiales o sociales. Boletín Oficial, 7 de noviembre de 1984. 
ARGENTINA. Ley 23.238, de 10 septiembre de1985. Reincorporación y reconocimiento del tiempo de inactividad a los efectos laborales y previsionales de los docentes, declarados prescindibles o cesantes por causas políticas, gremiales o conexas hasta el 9 de diciembre de 1983 inclusive. Boletín Oficial, 15 de octubre 1985.

. Ley 23.523, de 24 de junio de1987. Reingreso de agentes bancarios dejados cesantes por causas políticas o gremiales entre el 1 de enero de 1959 y el 10 de diciembre de 1983. Boletín Oficial, 28 de octubre de 1988.

Ley 23.278, de 28 de septiembre de 1985. Cómputo al sólo efecto jubilatorio de los períodos de inactividad comprendidos ante la vigencia de la ley 20.565, hasta el 9 de diciembre de 1983, para las personas que por motivos políticos o gremiales fueron dejadas cesantes, declaradas prescindibles o forzadas a renunciar a sus cargos. Boletín Oficial, 5 de noviembre de 1985.

. Ley 23492, de 29 de diciembre de 1986. "Punto Final". Boletín Oficial, 29 de diciembre de 1986.

. Ley 23521, de 4 de junio de 1987. "Obediencia Debida”. Boletin Oficial, 9 de junio de 1987.

. Ley 24.043, de 27 de noviembre de1991. Reparaciones a las personas que hubieran sido puestas a disposición del PEN durante la vigencia del estado de sitio o siendo civiles hubiesen sufrido detención en virtud de actos emanados de tribunales militares (observada la segunda oración del primer párrafo del art. 7). Promulgada por decreto 2722 del 23 de diciembre de 1991. Boletín Oficial, 2 de enero de 1992.

. Ley 24.41, de 7 de diciembre de 1994. Beneficios que tendrán derecho a percibir por medio de sus causahabientes personas que se encuentren en situación de desaparición forzada. Promulgada por decreto 2368/94. Boletín Oficial, 3 de enero de 1995. Decreto reglamentario 403/95 sancionado el 29 de agosto de 1995.

ASOCIACIÓN MADRES DE PLAZA DE MAYO. Nuestras consignas, Buenos Aires. Diciembre del 2005. Disponible en: <http://www.madres.org/navegar/ nav.php?idsitio $=5 \&$ idcat $=32 \& i d i n d e x=25>$. Acesso em: 1 nov. 2011 .

ARGENTINA. Corte Suprema de Justicia de la Nación. Yofre de Vaca Narvaja, Susana c/Mrio. del Interior resol. - M.J.D.H. 221/00. Y. 43. XXXVIII. Buenos Aires, Octubre del 2004. Disponible en: <http://www1.umn.edu/humanrts/ research/argentina/csjn2004Oct14Yofre.html>. Acesso em: 5 nov. 2011.

BOURDIEU, Pierre. La Economía de los Bienes Simbólicos. In: Razones Prácticas. Barcelona: Ed. Anagrama, 1997.

COMISION IDH, Informe Anual 28/92 OEA/Ser.L/V/II.83 Doc. 14, 12 marzo 1993. Disponible en: <http://www.oas.org >. Acesso em: 28 nov. 2011 
DA SILVA CATELA, Ludmila. No habrá flores en la tumba delpasado. La experiencia de reconstrucción del mundo de los familiares de desaparecidos. La Plata: Ed. Al Margen, 2001. . Desaparecidos e Direitos Humanos. Entre um drama nacional e um dilema universal. In: REYES NOVARES, Regina; KANT DE LIMA, Roberto (Org.). Antropología e Direitos Humanos. Río de Janeiro: Ed. da Universidade Federal Fluminense, 2001, p. 203-266.

DOMINIQUE, Temple. Teoría de la Reciprocidad. La Paz: Ed. Garza Azul, 2003. Disponible en: <www.iseatbolivia.org/.../11-librodomiqueiparte-1>. Acesso em: 1 nov. 2011.

EVANS PRITCHARD, Edwards. Los Nuer. Barcelona: Ed. Anagrama, 1977.

FIDALGO, Andrés. Jujuy, 1966/1983. Violaciones a Derechos Humanos cometidas en al territorio de la provincia o contra personas a ella vinculadas. Buenos Aires: Ed. La Rosa Blindada, 2001.

GUEMBE, María José. La Experiencia Argentina de Reparación Económica de Graves Violaciones a los Derechos Humanos. Buenos Aires: CELS, 2004. Disponible en: $<$ http://www.cels.org.ar/common/documentos/experiencia_argentina_reparacion.doc>. Acesso em: 12 nov. 2011.

JELIN, Elizabeth. Pan y afectos. La transformación de las familias. México: Fondo de Cultura Económica, 1998.

LA polémica de las reparaciones. Diario Página 12. Buenos Aires: 13 dic. 1998, p. 8 LAS Madres en la Bolsa de Comercio. Diario de las Madres. Buenos Aires, n. 145, Set. 1997, p. 11.

MARCANDO un camino. Periódico Denuncia, Washington: Año 6. n. 167, dic. 1980, 2p. Suplemento especial.

MAUSS, Marcel. Ensaios de sociología. Sāo Paulo: Ed. Perspectiva, 1979.

. Ensaio sobre a dádiva. Forma e razao da troca nas sociedades arcaicas. In: MAUSS, M. Sociología y Antropología. São Paulo: Ed. Edusp, 1974 [1923-1924], v. 2, p. $37-184$

REPARACIÓN económica, debate y reflexión. Diario de las Madres. Buenos Aires, Mayo 1997, n. 141, p.13.

SIGAUD, Lygia. Armadilhas da honra e do perdão: Usos sociais do direito na mata pernambucana. In: Maná Estudos de Antropologia Social, Rio de Janeiro, v. 10, n. 1 , p. 131-163, 2004

. Direito e coerção moral no mundo dos engenhos. In: Estudos históricos, v. 9 n. 18 , p. $361-388,1996$, 
TELLO, Mariana. La fuerza de la cosa dada: derechos humanos, política y moral en las "indemnizaciones" a las víctimas del terrorismo de estado en Argentina. In: Antropologia e direitos humanos II. Río de Janeiro: Ed. da Universidade Federal Fluminense, 2003. p. 37-74.

Recebido em: 28/05/2012

Aprovado em: 19/07/2012 